\title{
RETRACTED ARTICLE: How can SLCA influence change to a product's life cycle and who listens to the impacts of an SLCA?
}

\author{
Hee Sun Choi ${ }^{1}$
}

Received: 11 September 2014/ Accepted: 10 April 2015/Published online: 24 April 2015

(C) Springer Science+Business Media Dordrecht 2015

This article has been retracted by the Editor-in-Chief because the author did not have permission (implicit or explicit) to publish this data in our journal. The results presented in this work were obtained under supervision of Dr Choi's former colleagues at the University of Oxford, and were included without their knowledge or permission. Given the copyright and authorship issues involved, the Environment, Development, and Sustainability article in question is being retracted.

The online version of this article contains the full text of the retracted article as electronic supplementary material.

Electronic supplementary material The online version of this article (doi:10.1007/s10668-015-9662-x) contains supplementary material, which is available to authorized users.

Hee Sun Choi

hee_sun26@hotmail.com; sunny.choi@ouce.ox.ac.uk

1 School of Geography and the Environment, University of Oxford, South Park Road,

Oxford OX1 3QY, UK 